\title{
A Linearly Polarized Patch Antenna for Ultra-Wideband Applications
}

\author{
P. Kumar ${ }^{1,2}$ \\ ${ }^{1}$ Discipline of Electrical, Electronics and Computer Engineering, \\ School of Engineering, Howard College Campus, \\ University of Kwazulu-Natal, King George V Avenue, Durban-4041, South Africa \\ ${ }^{2}$ Department of Electronics and Communication Engineering \\ Jaypee University of Information Technology, Waknaghat, India \\ pkumar_123@yahoo.com
}

\begin{abstract}
This paper presents a linearly polarized monopole antenna for ultra-wideband applications. Two different monopole antennas are presented for the lower and upper band of ultra wideband. Two antennas together can be used for the entire ultra-wideband. The designed models of antennas are simulated and optimized using CST Microwave studio. The simulated antenna performance parameters are presented. The reflection coefficient is less than $-10 \mathrm{~dB}$ for the frequency range $3.4261 \mathrm{GHz}-$ 10.939 $\mathrm{GHz}$. The maximum directivity of $3.37 \mathrm{dBi}$, and $6.151 \mathrm{dBi}$ are achieved for lower band antenna of upper band antenna, respectively. The radiation patterns of the antenna show omnidirectional behavior of the antennas.
\end{abstract}

Keyword-Monopole, ultra-wideband, reflection coefficient, radiation pattern

\section{INTRODUCTION}

The Federal Communication Commission (FCC) allotted the frequency band $3.1 \mathrm{GHz}-10.6 \mathrm{GHz}$ as unlicensed band. This unlicensed band is known as ultra-wideband. The ultra-wideband provides a wide bandwidth which is a key requirement of the modern wireless communication systems [1-3].

The microstrip antennas have many advantages over other antennas such as compact size, easy to fabricate, low cost etc. Due to several advantages of these antennas over other types of antennas, these antennas are used in various wireless applications such as missile, aircraft, mobile handsets etc [4]. However, these antennas suffer with some limitations such as low gain and wider bandwidth. The conventional microstrip antennas have2-5\% bandwidth [5], however microstrip antennas for ultra-wideband needs approximately $110 \%$ bandwidth. There are various techniques in literature for improving the bandwidth of microstrip antennas such as gap-coupling [68], stacked-coupling [9-10], shorting post [11] etc. Researchers are continuously working on this issue and recently proposed various designs of ultra-wideband antennas [12-16]. In [12], the novel antennas are presented for ultra-wideband applications using two different structures. First antenna is fed by microstrip line and the second is a compact coplanar waveguide fed planar slot antenna.In [13], a multiple input multiple output (MIMO) antenna is designed for ultra-wideband applications. In [14], an ultra-wideband (UWB) antenna is reported for a microwave imaging system. The structure utilizes a very simple Hibiscus petal pattern patch with tapered microstrip line feeding and partial trapezoid ground plane. The gap between the Hibiscus petal pattern patch and partial ground of the antenna is optimized to achieve ultra-wideband operation. In [15], two orthogonal monopoles are used to design a dual polarized ultra-wideband antenna. In [16], a low-cost coplanar waveguide fed compact ultra-wideband (UWB) antenna is presented. The designed antenna eliminates the wireless local area network (WLAN) signals. The notch band characteristic is achieved by etching half wavelength C-shaped annular ring slot in the radiating patch. Polarization of the microstrip antennas also plays an important role in the performance of the wireless communication system. A polarization matched linearly polarized antenna is more efficient as compared to the circularly polarized antenna systems, however in circularly polarized antennas polarization matching is not required [4].

In this paper a linearly polarized microstrip patch antenna is presented. Two different antennas are designed for lower and upper band of the ultra-wideband to achieve the entire ultra-wideband operation. Rest of the paper is organized as follows: section 2 presents the geometry of the antenna.The various parameters of the designed antennaalong with their description are presentedin section 3. The conclusion of the presented work is given in section 4 .

\section{ANTENNA GEOMETRY}

The geometry of the antenna is given in Fig 1. The monopole is divided in to two sections as shown in Fig. 1. These two sections give extra freedom to optimize the design. The length and width of first section are $L_{1}$ and $w_{1}$ respectively. The length and width of second section are $L_{2}$ and $w_{2}$ respectively. The monopole is fed by coaxial feeding technique. The ground plane is optimized to achieve the optimum performance of the antenna. The thickness and dielectric constant of the substrate are $h$ and $\varepsilon_{r}$, respectively. 


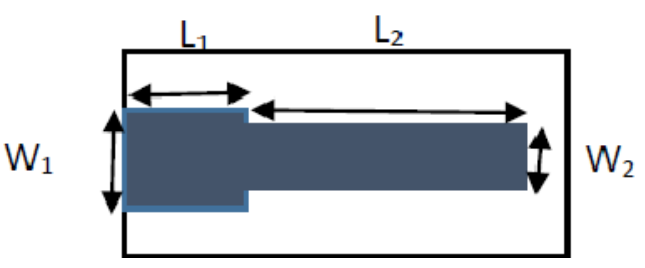

(a)

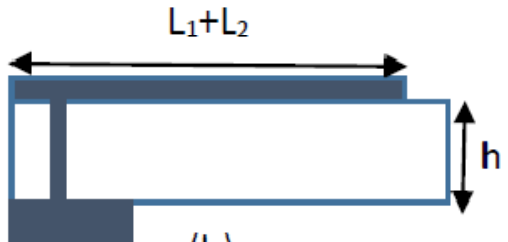

(b)

Fig. 1 Geometry of the antenna.

\section{III.RESULTS AND DISCUSSION}

The antenna structure shown in Fig. 1 is optimized for lower and upper band of ultra-wideband using CST microwave studio. The antenna 1 is optimized for the lower band of the ultra-wideband and antenna 2 is optimized for the upper band of the ultra-wideband. The optimized dimensions of the designed antenna are given in Table I.With the optimized dimensions the antenna parameters of the simulated model are studied. The reflection coefficient of the antenna 1 is depicted in Fig. 2. The reflection coefficient of the antenna 1 is less than $-10 \mathrm{~dB}$ for the bandwidth of $3.4261 \mathrm{GHz}$ to $5.8415 \mathrm{GHz}$ as shown in Fig. 2. Fig. 3 shows the reflection coefficient of the designed antenna 2 for the upper band of the ultra-wideband. From Fig. 3, it can be observed that the reflection coefficient of the antenna is less than $-10 \mathrm{~dB}$ for the bandwidth $5.1204 \mathrm{GHz}$ to $10.939 \mathrm{GHz}$. Both the antennas together can be used for the bandwidth $3.4261 \mathrm{GHz}$ to $10.939 \mathrm{GHz}$, which very much closed to the ultra-wideband.

Further the radiation patterns of the antenna 1 at $3.5 \mathrm{GHz}, 4 \mathrm{GHz}, 4.5 \mathrm{GHz}$ and $5 \mathrm{GHz}$ are shown in Fig. 4(a), Fig. 4(b), Fig. 4(c), and Fig. 4 (d), respectively. The radiation patterns in $H$-plane show the omnidirectional behavior of the designed antenna. Fig. 5 (a), Fig. 5(b), Fig. 5(c), Fig. 5(d) and Fig. 5(e) show the $E$-plane and $H$ plane radiation patterns at $5 \mathrm{GHz}, 6.5 \mathrm{GHz}, 8 \mathrm{GHz}, 9.3 \mathrm{GHz}$, and $10 \mathrm{GHz}$, respectively. The radiation patters of the antenna 2 show its omnidirectional behavior in both the planes.

TABLE I. Optimized dimensions of the designed antennas

\begin{tabular}{|c|c|l|c|l|}
\hline \multirow{2}{*}{ S. No. } & \multicolumn{2}{|c|}{ Antenna 1 } & \multicolumn{2}{c|}{ Antenna 2 } \\
\cline { 2 - 5 } & Dimension & Size (mm) & Dimension & Size (mm) \\
\hline 1 & $L_{1}$ & 2 & $L_{1}$ & 6.5 \\
\hline 2 & $w_{1}$ & 2.7 & $w_{1}$ & 3.5 \\
\hline 3 & $L_{2}$ & 21 & $L_{2}$ & 8 \\
\hline 4 & $w_{2}$ & 1.9 & $w_{2}$ & 2.2 \\
\hline 5 & $h$ & 1.58 & $h$ & 1.58 \\
\hline 6 & $\varepsilon_{r}$ & 4.9 & $\varepsilon_{r}$ & 4.9 \\
\hline
\end{tabular}

The maximum directivity, radiation efficiency and total efficiency of the antennas 1 at $3.5 \mathrm{GHz}, 4 \mathrm{GHz}, 4.5$ $\mathrm{GHz}$, and $5 \mathrm{GHz}$ are given in Table II. Other parameters of the designed antenna 1. A maximum directivity of $3.37 \mathrm{dBiis}$ achieved for the antenna 1. Table III presents the maximum directivity, radiation efficiency and total efficiency at various frequencies of the antenna 2. The maximum directivity of $6.151 \mathrm{dBiis}$ achieved for antenna 2. The 3-dB beamwidths for E-plane and $\mathrm{H}$-plane at various frequencies, for antenna 1 and antenna 2, are given in Table IV and in Table $\mathrm{V}$, respectively. 


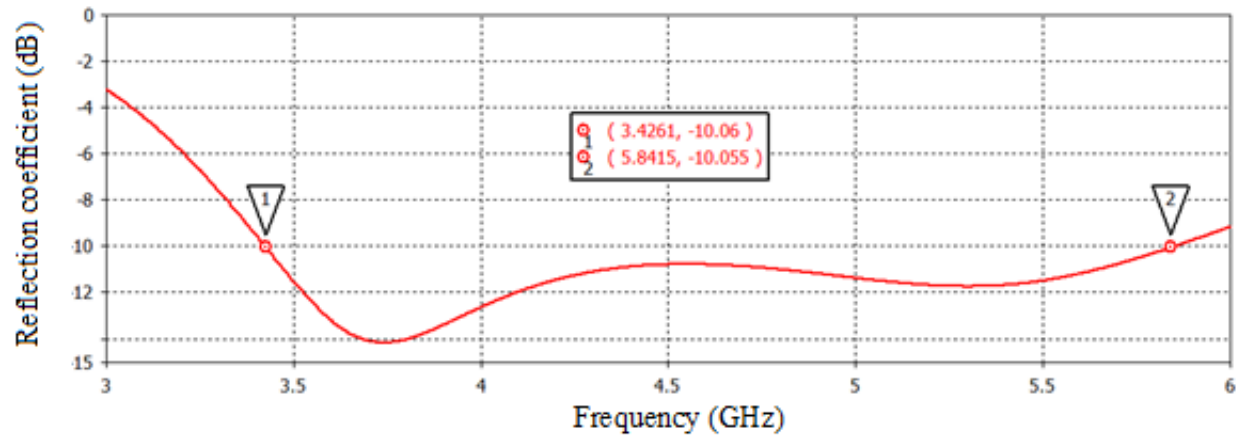

Fig. 2 Reflection coefficient of antenna 1.

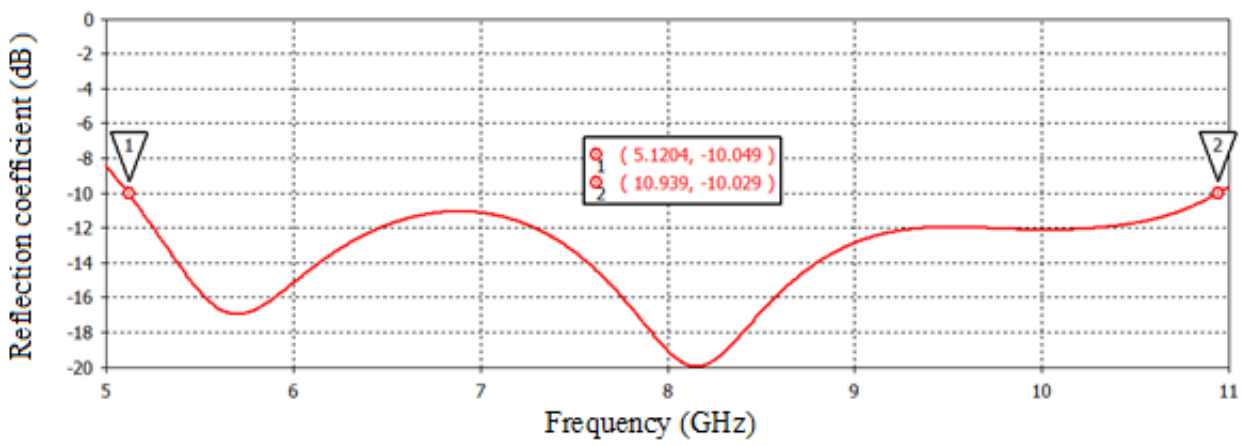

Fig. 3 Reflection coefficient of antenna 2.

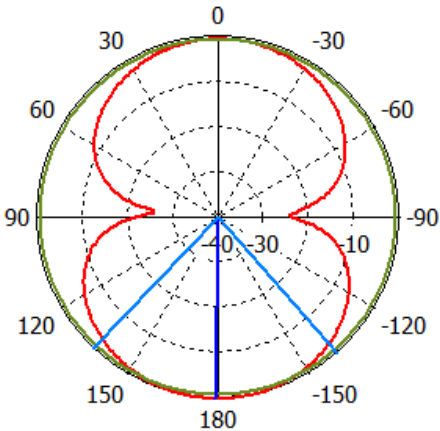

E-plane

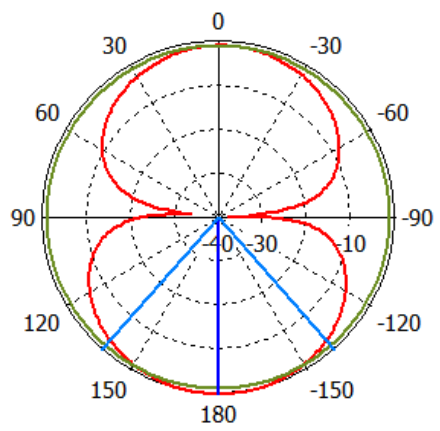

$E$-plane

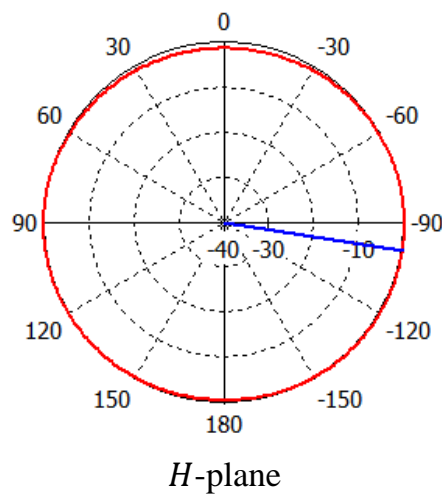

(a)

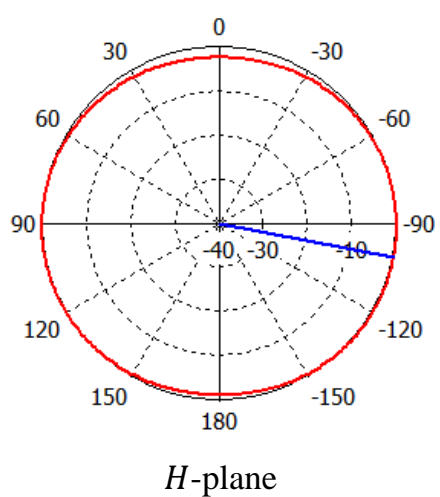

(b) 

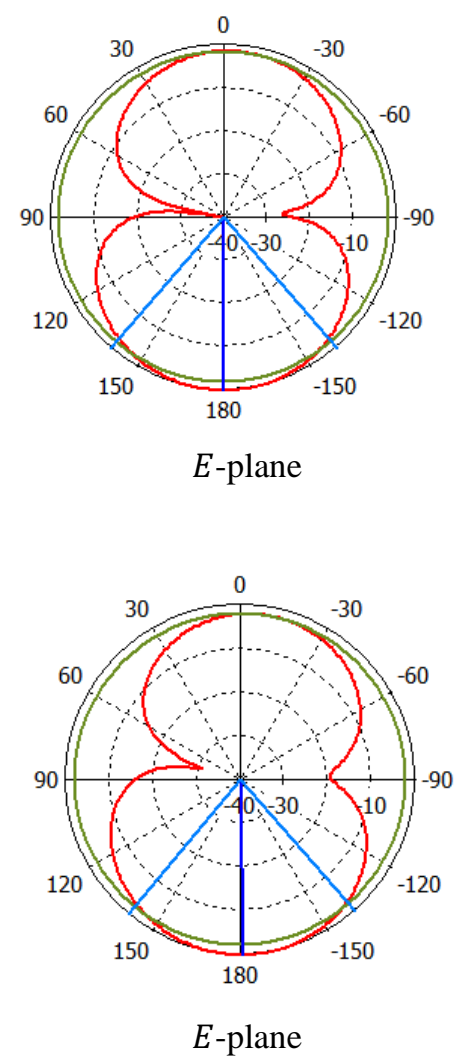

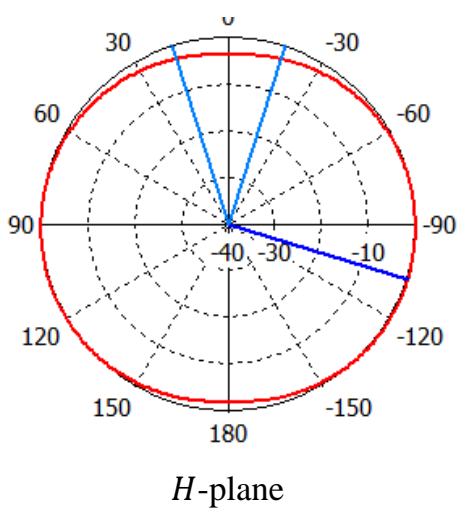

(c)

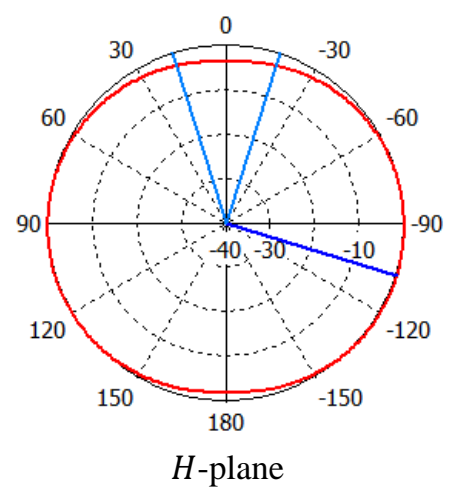

(d)

Fig. 4 Radiation patters of antenna 1 at (a) $3.5 \mathrm{GHz}$, (b) $4 \mathrm{GHz}$, (C) $4.5 \mathrm{GHz}$, and (d) $5 \mathrm{GHz}$

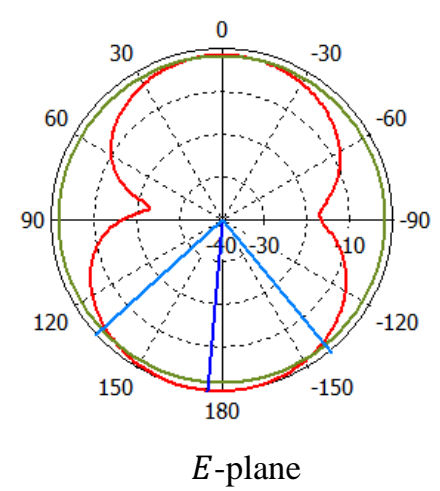

(a)
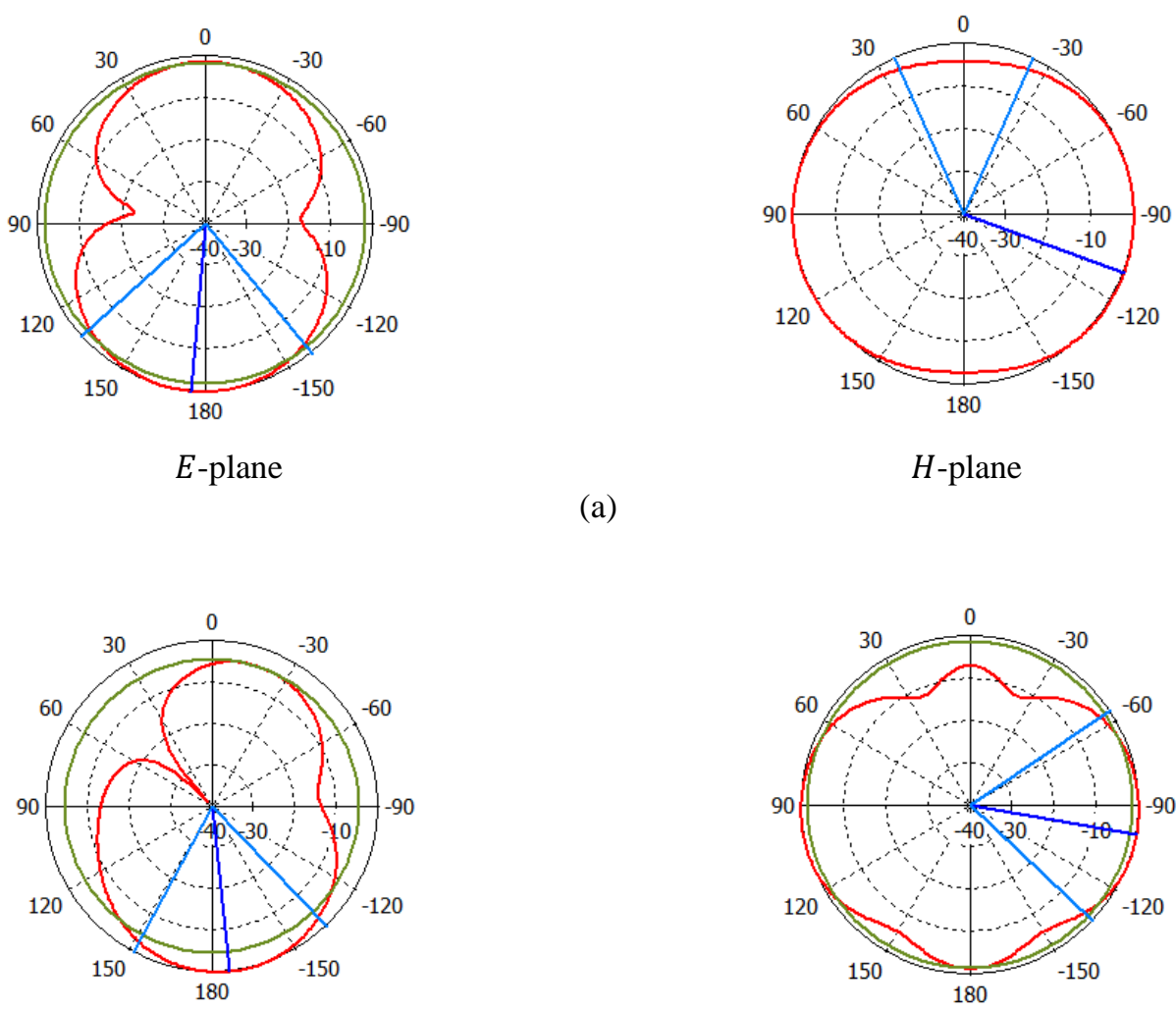

E-plane

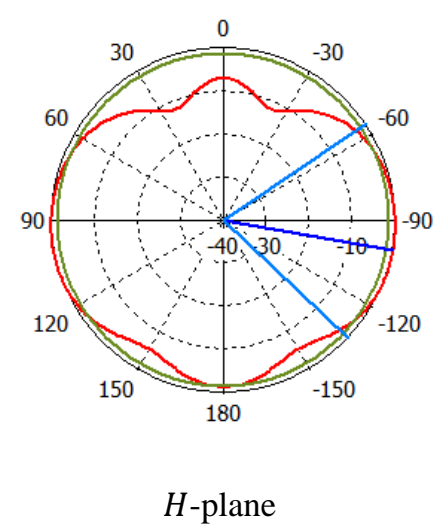

(b) 

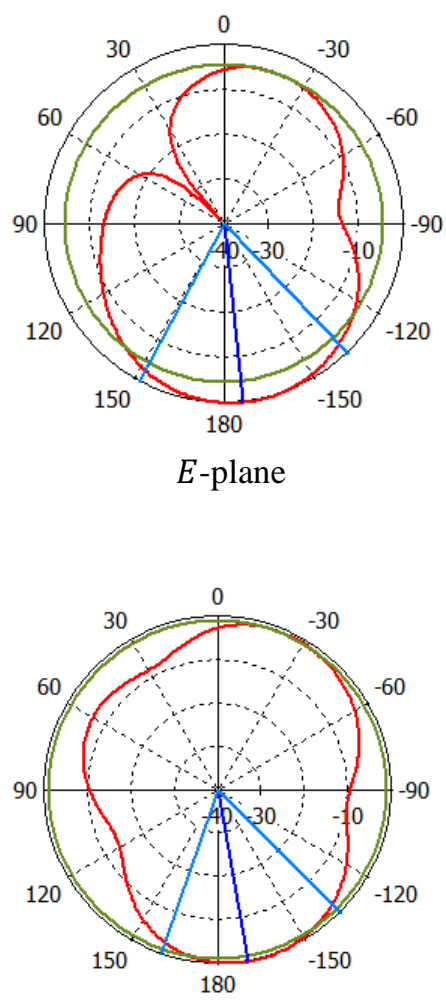

E-plane

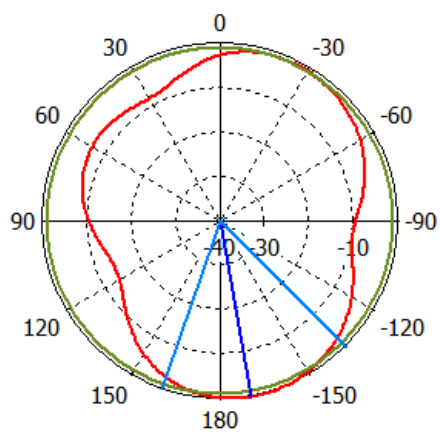

$E$-plane

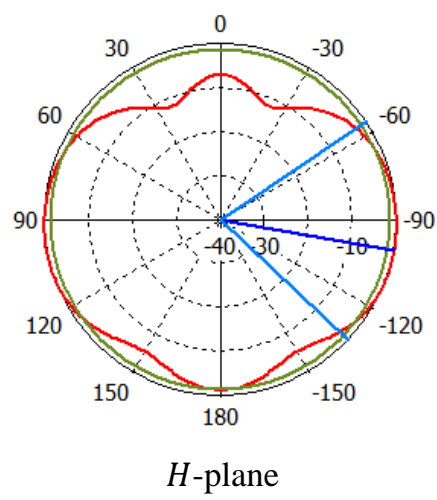

(c)

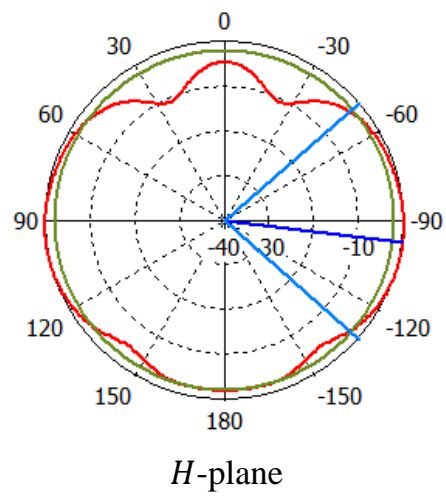

(d)

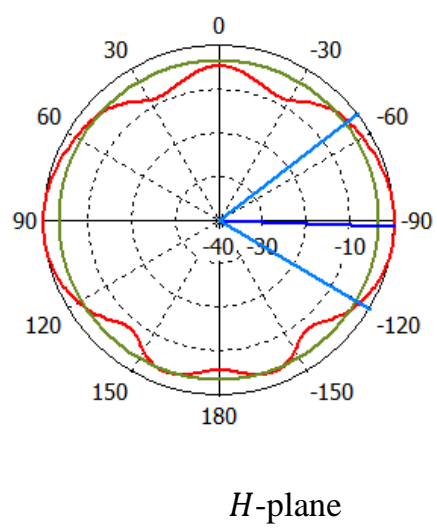

(e)

Fig. 5 Radiation patterns of antenna 2 at (a) $5 \mathrm{GHz}$, (b) $6.5 \mathrm{GHz}$, (c) $8 \mathrm{GHz}$, (d) $9.3 \mathrm{GHz}$, and (e) $10 \mathrm{GHz}$

TABLE II. Max. directivity, radiation efficiency and total efficiency of the designed antenna 1

\begin{tabular}{|l|l|l|}
\hline Antenna Parameter & Frequency & Value \\
\hline Max. Directivity & $3.5 \mathrm{GHz}$ & $2.464 \mathrm{dBi}$ \\
\cline { 2 - 3 } & $4 \mathrm{GHz}$ & $2.856 \mathrm{dBi}$ \\
\cline { 2 - 3 } & $4.5 \mathrm{GHz}$ & $3.217 \mathrm{dBi}$ \\
\cline { 2 - 3 } & $5 \mathrm{GHz}$ & $3.37 \mathrm{dBi}$ \\
\hline Radiation Efficiency & $3.5 \mathrm{GHz}$ & $93.76 \%$ \\
\cline { 2 - 3 } & $4 \mathrm{GHz}$ & $94.41 \%$ \\
\cline { 2 - 3 } & $4.5 \mathrm{GHz}$ & $92.5 \%$ \\
\cline { 2 - 3 } & $5 \mathrm{GHz}$ & $91.31 \%$ \\
\hline Total Efficiency & $3.5 \mathrm{GHz}$ & $87.15 \%$ \\
\cline { 2 - 3 } & $4 \mathrm{GHz}$ & $89.27 \%$ \\
\cline { 2 - 3 } & $4.5 \mathrm{GHz}$ & $84.91 \%$ \\
\cline { 2 - 3 } & $5 \mathrm{GHz}$ & $84.67 \%$ \\
\hline
\end{tabular}


TABLE III. Max. directivity, radiation efficiency and total efficiency of the designed antenna 2

\begin{tabular}{|l|l|l|}
\hline Antenna Parameter & Frequency & \multicolumn{1}{|c|}{ Value } \\
\hline Max. Directivity & $5 \mathrm{GHz}$ & $3.153 \mathrm{dBi}$ \\
\cline { 2 - 3 } & $6.5 \mathrm{GHz}$ & $5.48 \mathrm{dBi}$ \\
\cline { 2 - 3 } & $8 \mathrm{GHz}$ & $5.48 \mathrm{dBi}$ \\
\cline { 2 - 3 } & $9.3 \mathrm{GHz}$ & 5.429 \\
\cline { 2 - 3 } & $10 \mathrm{GHz}$ & $6.151 \mathrm{dBi}$ \\
\hline Radiation Efficiency & $5 \mathrm{GHz}$ & $93.26 \%$ \\
\cline { 2 - 3 } & $6.5 \mathrm{GHz}$ & $86.67 \%$ \\
\cline { 2 - 3 } & $8 \mathrm{GHz}$ & $86.67 \%$ \\
\cline { 2 - 3 } & $9.3 \mathrm{GHz}$ & $83.93 \%$ \\
\cline { 2 - 3 } & $10 \mathrm{GHz}$ & $82.69 \%$ \\
\hline \multirow{5}{*}{ Total Efficiency } & $5 \mathrm{GHz}$ & $79.93 \%$ \\
\cline { 2 - 3 } & $6.5 \mathrm{GHz}$ & $85.59 \%$ \\
\cline { 2 - 3 } & $8 \mathrm{GHz}$ & $85.59 \%$ \\
\cline { 2 - 3 } & $9.3 \mathrm{GHz}$ & $78.72 \%$ \\
\cline { 2 - 3 } & $10 \mathrm{GHz}$ & $77.6 \%$ \\
\hline
\end{tabular}

TABLE IV. 3-dB beamwidth for Antenna 1

\begin{tabular}{|l|l|l|}
\hline \multirow{2}{*}{ Frequency } & \multicolumn{2}{|c|}{ Beamwidth } \\
\cline { 2 - 3 } & E-plane & H-plane \\
\hline $3.5 \mathrm{GHz}$ & $84.5^{\circ}$ & Entire plane \\
\hline $4 \mathrm{GHz}$ & 82.8 & Entire plane \\
\hline $4.5 \mathrm{GHz}$ & 81.7 & 325 \\
\hline $5 \mathrm{GHz}$ & 80.6 & 325 \\
\hline
\end{tabular}

TABLE V. 3-dB beamwidth for Antenna 2

\begin{tabular}{|l|l|l|}
\hline \multirow{2}{*}{ Frequency } & \multicolumn{2}{|c|}{ Beamwidth } \\
\cline { 2 - 3 } & E-plane & H-plane \\
\hline $5 \mathrm{GHz}$ & 87.5 & 312.4 \\
\hline $6.5 \mathrm{GHz}$ & 72.3 & 77.6 \\
\hline $8 \mathrm{GHz}$ & 72.3 & 77.6 \\
\hline $9.3 \mathrm{GHz}$ & 64.5 & 82.8 \\
\hline $10 \mathrm{GHz}$ & 64.5 & 68.3 \\
\hline
\end{tabular}

\section{IV.CONCLUSION}

The design of a single polarized monopole antenna has been presented. Two antennas for lower and upper band of ultra-wideband are presented to achieve the ultra-wideband operation. The designs of both antennas are optimized using CST microwave studio. Various input and directional parameters of the designed antennas have been shown and explained. From these parameters it can be concluded that the designed individual two antennas can be used for lower and upper band of the ultra-wideband and these antennas together can be used for the ultra-wideband applications with reasonable directivity and omnidirectional nature of the radiation patterns.

\section{REFERENCES}

[1] Z.N. Chen, X.H. Wu, H.F. Li, and M.Y. Chia, Considerations for source pulses and antennas in UWB radio systems, IEEE Trans. onAntennasPpropag, vol. 52 , pp. 1739-1748, 2004.

[2] K. Siwiak and D. McKeown, Ultra-Wideband Radio Radio Technology, Wiley, Hoboken, NJ, 2004.

[3] R.J. Cramer, R.A. Scholtz, and M. .Z. Win, Evaluation of an ultrawideband propagation channel, IEEE Trans onAntennas Propag, vol. 50, pp. 561-570, 2002.

[4] C. A. Balanis, Antenna Theory-Analysis and Design, John wiley and sons, 2005.

[5] V. R. Ekke, P. L. Zade, Design and Implementation of T-junction Triangular Microstrip Patch Antenna Array for Wireless Applications, International Journal of Engineering and Technology, vol. 8, no. 5, pp. 2105-2114, 2016.

[6] P. Kumar and G. Singh, Gap-coupling: a potential method for enhancing the bandwidth of microstrip antennas, Advanced Computational Techniques in Electromagnetics, vol. 2012, pp. 1-6, 2012.

[7] P. Kumar, Computation of resonant frequency of gap-coupled ring microstrip antennas, International Journal of Automation and Computing, vol. 11, no. 6, pp. 671-675, 2014. 
[8] P. Kumar, G. Singh, S. Bhooshan, T. Chakravarty Gap - coupled microstrip antennas, Proc. of International Conference on Computational Intelligence and Multimedia Applications, pp. 434-437, 2007.

[9] D. Sun, W. Dou, L. You, X. Yan, and R. Shen, A broadband proximity-coupled stacked microstrip antenna with cavity-backed configuration, IEEE Antennas and Wireless Propagation Letters, vol. 10, pp. 1055-1058, 2011.

[10] P. Kumar, and N. Bisht, Stacked coupled circular microstrip patch antenna for dual band applications, Proc. of Progress in Electromagnetics research symposium, Suzhou, China, pp. 629-632, 2011.

[11] P. Kumar and G. Singh, Microstrip antennas loaded with shorting post, Engineering, vol. 1, pp. 1-54, 2009.

[12] F. B. Ghenaya, R. Ghayoula and A. Gharsallah, A novel linear array antenna based on UWB slot antenna, American Journal of Applied Sciences, vol. 13, no. 3, pp. 290-298, 2016.

[13] J. J. Yak, and A. H. A. Shamsi, MIMO antenna for uwb communications, Int. J. Communications, Network and System Sciences, vol. 9, pp. 177-183, 2016.

[14] M. Z. Mahmud, M. T. Islam, and M. Samsuzzaman, A high performance UWB antenna design for microwave imaging system, Microwave and Optical Technology Letters, vol. 58, no. 8, pp. 1824-1831, 2016.

[15] P. Kumar and J. L. Masa-Campos, Dual polarized microstrip patch antennas for ultra-wideband applications, Microwave and Optical Technology Letters, vol. 56, no. 9, pp. 2174-2179, 2014.

[16] A. Syed and R. W. Aldhaheri, A very compact and low profile uwb planar antenna with WLAN band rejection”, The Scientific World Journal, vol. 2016, pp. 1-7, 2016.

\section{AUTHOR PROFILE}

P.Kumar received Bachelor, Masters and Doctoral degrees in Electronics and Comm.Engg.from Institute of Engineering and Technology, R. U. Campus,Thapar Institute of Engineering and Technology (Deemed University), and JaypeeUniversity of Information Tech., Solan, respectively. He was associated with UAM Madrid, Spain as postdoctoral fellow.He is the author of many research papers published in various national/international journals/conferences. At present, he is working as a faculty member in the Discipline of Electrical, Electronic and Computer Engineering, University of Kwazulu-Natal, Durban, South Africa. His research area includes Design and Analysis of Microstrip Antennas, Antenna Arrays, Signal and Image Processing. 